\title{
Are family planning vouchers effective in increasing use, improving equity and reaching the underserved? An evaluation of a voucher program in Pakistan
}

\author{
Moazzam Ali ${ }^{1 *}$ (D) Syed Khurram Azmat ${ }^{2,3}$, Hasan Bin Hamza ${ }^{4}$, Md. Mizanur Rahman ${ }^{5}$ and Waqas Hameed ${ }^{6}$
}

\begin{abstract}
Background: Low modern contraceptive prevalence rate and high unmet need in Pakistan aggravates the vulnerabilities of unintended pregnancies and births contributing to maternal morbidity and mortality. This research aims to assess the effectiveness of a free, single-purpose voucher approach in increasing the uptake, use and better targeting of modern contraceptives among women from the lowest two wealth quintiles in rural and urban communities of Punjab province, Pakistan.

Methods: A quasi-interventional study with pre- and post-phases was implemented across an intervention (Chakwal) and a control district (Bhakkar) in Punjab province (August 2012-January 2015). To detect a 15\% increase in modern contraceptive prevalence rate compared to baseline, 1276 women were enrolled in each arm. Difference-in-Differences (DID) estimates are reported for key variables, and concentration curves and index are described for equity.

Results: Compared to baseline, awareness of contraceptives increased by 30 percentage points among population in the intervention area. Vouchers also resulted in a net increase of $16 \%$ points in current contraceptive use and $26 \%$ points in modern methods use. The underserved population demonstrated better knowledge and utilized the modern methods more than their affluent counterparts. Intervention area also reported a low method-specific discontinuation (13.7\%) and high method-specific switching rates (46.6\%) amongst modern contraceptive users during the past 24 months. The concentration index indicated that voucher use was more common among the poor and vouchers seem to reduce the inequality in access to modern methods across wealth quintiles.

Conclusion: Vouchers can substantially expand contraceptive access and choice among the underserved populations. Vouchers are a good financing tool to improve equity, increase access, and quality of services for the underserved thus contributing towards achieving universal health coverage targets.
\end{abstract}

Keywords: Vouchers, Contraceptives, Family planning, Equity, Pakistan

\footnotetext{
*Correspondence: alimoa@who.int

'Department of Reproductive Health and Research, World Health

Organization, Avenue Appia 20, CH-1211 Geneva 27, Switzerland

Full list of author information is available at the end of the article
}

(c) The Author(s). 2019 Open Access This article is distributed under the terms of the Creative Commons Attribution 4.0 International License (http://creativecommons.org/licenses/by/4.0/), which permits unrestricted use, distribution, and reproduction in any medium, provided you give appropriate credit to the original author(s) and the source, provide a link to the Creative Commons license, and indicate if changes were made. The Creative Commons Public Domain Dedication waiver (http://creativecommons.org/publicdomain/zero/1.0/) applies to the data made available in this article, unless otherwise stated. 


\section{Background}

High population growth and fertility rates affect human development and adversely impact the health and lives of women and children [1]. Pakistan has a high total fertility rate (TFR) of 3.8 [2] and low modern contraceptive prevalence rate (mCPR) i.e. 26\% [2], combined with a high unmet need of about $20 \%$. Short-term methods are widely known and used compared to long-term methods [2].

The health system in Pakistan suffers from significant urban-rural disparities in healthcare delivery [1]. Data from the 2012-13 Pakistan Demographic Health Survey (PDHS) described that the poorest people in Pakistan, in particular rural residents, experience significant difficulty in gaining access to essential health services, including FP provided by public and private sectors [2]. The modern contraceptive uptake was 23 and $20 \%$ in the rural and in the poorest populations, respectively along with a high unmet need [1-3]. According to Pakistan Demographic Health Surveys from 1990 onwards the private sector provision of share of family planning services in the country increased from 34 to $52 \%$ specially in the rural and poorest populations $[2,4-6]$.

Traditionally the health sector focus has been to improve supply side with a lesser focus on utilizing demand side approaches in FP [7, 8]. Recently the emphasis has shifted towards improving the physical, financial and social access of marginalized populations to FP services using social franchising approaches including vouchers [8-19]. However, the current evidence on the effectiveness of voucher approaches seems limited [15, 17], thus highlighting the need to fill the knowledge gaps. [2, 15, 20, 21]. As most of the modern contraceptive method users obtain services through the private sector in Pakistan the lack of financial resources at the individual level can be a major impediment in acquiring FP services $[2,4]$.

The Family Planning 2020 (FP2020) goals are to reach 120 million more women with voluntary family planning services through the expansion of global access to family planning [22]. The intended outputs of the FP2020 goal are universal access, efficiency, quality and equity [18]. Demand Side Financing (DSF) approaches, including vouchers, aim to address some of the economic and structural barriers that limit the uptake of FP $[15,25-$ 28 ] which involves transferring purchasing power to specified groups for the purchase of defined goods or services. $[25,27]$. Some voucher schemes have been shown to be limitedly effective in countries like Bangladesh, India, Kenya, Indonesia, Pakistan, Ethiopia and Uganda $[4,11,12,15,17,20,23-25,29-31]$.

The paper reports a study conducted by Marie Stopes Society (MSS) Pakistan (the local affiliate of Marie Stopes International (MSI) in Pakistan) to assess the effectiveness of a free, single-purpose voucher approach (MSS model) in increasing the access, uptake, improving equity and better targeting of modern contraceptives among women from the lowest two wealth quintiles in rural and urban communities of Punjab province, Pakistan [8, 17, 32, 33].

\section{Methods}

MSS used a combination of social franchising and voucher program to reach out to the underserved in selected areas in Punjab province, Pakistan to increase access to all methods with a special focus on long acting reversible contraceptives (LARCs). It had a quasi-interventional study design with pre and post phases implemented through an intervention, with a control arm. For the pre-intervention phase an independent cross-sectional baseline survey was conducted in May 2012 in the intervention and control arms. The intervention phase ended in January 2015, followed by an independent cross-sectional end line assessment through employing a household cross-sectional survey in the intervention and control arms between JanuaryMarch 2015.

The study had an implementation arm in Chakwal and the control arm in Bhakkar districts in Punjab province, Pakistan. These districts were selected based on the basis of comparable socio-demographic and health indicators (Table 1) and distance between intervention and control districts to minimize contamination. Mianwali, was taken as second intervention district, but had to be dropped off due to security reasons and the data were omitted from the analysis (only baseline was conducted).

\section{Study intervention}

Although, the details of study intervention/s package is reported in the published protocol [8]. However in brief, the MSS project is a single-purpose voucher approach and assumed that affordability was a barrier to women accessing FP services. Keeping this in mind, MSS Pakistan tested a single-purpose voucher intervention delivered to clients through an established SF network. The salient features of the intervention included the following:

- Vouchers provided only for free FP services.

- The vouchers provided three pre-paid FP visits.

- The visits were for follow-up, side-effect management and removal of FP method if required.

- Both short- and long-term contraceptive methods were provided during the visit.

- Community-level providers such as Lady Health Visitors or equivalent were trained to provide FP services, including long-term methods such as 
Table 1 Characteristics of intervention and control districts in Punjab province

\begin{tabular}{|c|c|c|c|}
\hline \multirow[t]{2}{*}{ Indicator } & \multicolumn{2}{|c|}{$\begin{array}{l}\text { Selected districts in } \\
\text { Punjab Province }\end{array}$} & \multirow[t]{2}{*}{$\begin{array}{l}\text { Punjab } \\
\text { Province }\end{array}$} \\
\hline & $\begin{array}{l}\text { Chakwal } \\
\text { (Intervention) }\end{array}$ & $\begin{array}{l}\text { Bhakkar } \\
\text { (Control) }\end{array}$ & \\
\hline $\begin{array}{l}\text { Estimated population size (2011 } \\
\text { estimated) }\end{array}$ & $1,376,000$ & $1,335,000$ & \\
\hline $\begin{array}{l}\% \text { of pop. who are female } \\
\text { aged } 15-49\end{array}$ & 25 & 22.0 & 22.3 \\
\hline $\begin{array}{l}\text { Contraceptive Prevalence } \\
\text { Rate (CPR) }\end{array}$ & 29 & 20 & 32 \\
\hline Modern methods & 23 & 17.3 & 25.1 \\
\hline Traditional methods & 5.5 & 2.7 & 7.1 \\
\hline $\begin{array}{l}\% \text { literate (among survey } \\
\text { respondents) }\end{array}$ & 56.7 & 51.3 & 46.6 \\
\hline$\%$ Wall material Kacha ${ }^{a}$ & 14 & 35.5 & 22 \\
\hline$\%$ Roof material Kacha & 0.9 & 26.5 & 15.8 \\
\hline $\begin{array}{l}\% \text { Unemployed (among survey } \\
\text { respondents) }\end{array}$ & 12.4 & 6.7 & 6.8 \\
\hline $\begin{array}{l}\text { Ever user of contraception but not } \\
\text { current }\end{array}$ & 6.7 & 3.0 & 4.3 \\
\hline Infant mortality rate & 60 & 82 & 77 \\
\hline Under 5 mortality rate & 82 & 119 & 111 \\
\hline$\%$ of households with television & 71 & 49.1 & 63 \\
\hline$\%$ of households with electricity & 94 & 90.0 & 92.5 \\
\hline
\end{tabular}

intrauterine contraceptive devices (IUDs) and implants (provided by doctors).

- Community outreach workers - called field health educators (FHE) - assessed women for poverty and the need for FP and also counselled them for FP. Women living in poverty were those who belonged to the poorest two quintiles using MSS' poverty assessment (adapted) tool.

\section{Study participants}

Through a multi-stage sampling strategy, women aged 18-49 years (including, but not limited to post-partum women) were recruited for the baseline and end line household surveys. We also used stratified sampling in the intervention district to ensure that we recruit sufficient number of voucher clients (see Fig. 1).

\section{Sample size determination}

The sample size was calculated assuming that the modern method CPR would increase by up to 20 percentage points from the baseline to the end line in the intervention area and that, in the control area, it would increase by 5 percentage-points between baseline and end line. Using PASS 11 software, it was estimated that group sample sizes of at least 1276 for intervention arm and 1276 for control arm would produce a two-sided 95\% confidence interval for the difference in population proportions with a width of $5 \%$ when the estimated sample proportion ' 1 ' is $20 \%$, the estimated sample proportion ' 2 ' is $5 \%$, and the difference in sample proportions is $15 \%$.

\section{Stratified sampling}

To ascertain success of vouchers in targeting poor women, it was estimated to have at least 360 voucher clients assuming a logistic regression of a binary response variable $(\mathrm{Y})$ on a binary independent variable $(\mathrm{X})$ would achieve $80 \%$ power at a 0.05 significance level to detect an odds ratio of 3.0.

We therefore used stratified sampling by recruiting respondents from the general population (strata 1) and voucher clients (strata 2). To ensure we recruited at least 360 voucher clients we allocated the required sample size (1276) for intervention district in two strata in a 3.5:1 (general population: voucher client) ratio. Therefore, we planned to recruit at least 916 respondents from

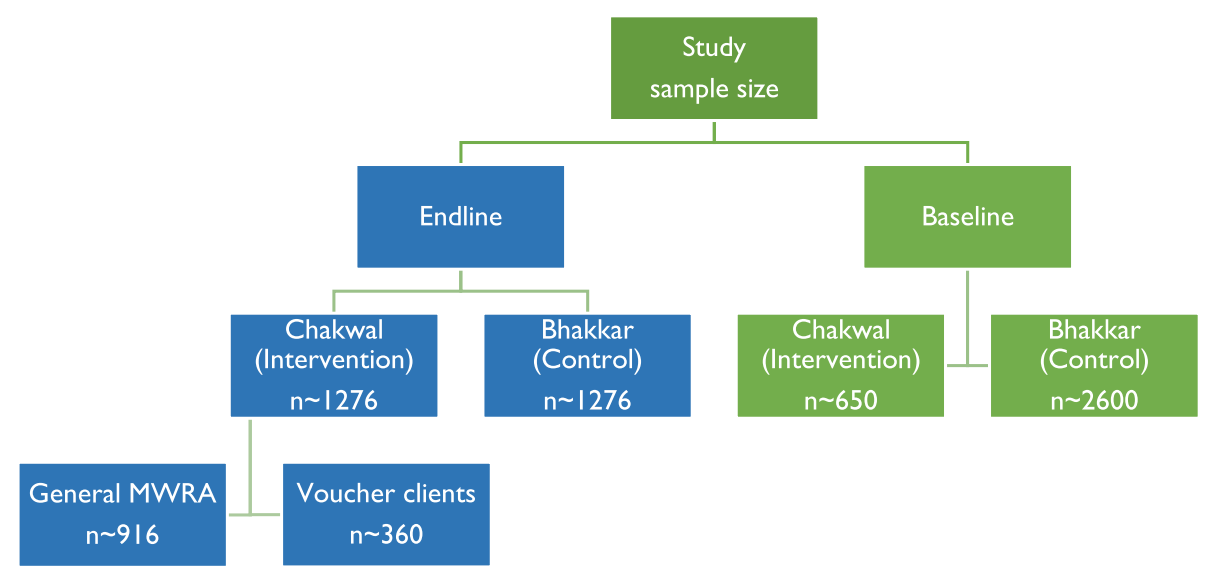

Fig. 1 Estimated sample size distribution 
the general population (strata 1) and at least 360 voucher clients (strata 2) in the intervention arm (See above Fig. 1).

\section{Sampling procedure}

A multi-stage sampling strategy was used to recruit study participants for the end line household survey. At the first stage, catchment areas of the project clinics were refreshed from baseline within the intervention and control districts. These areas covered a $3-4 \mathrm{~km}$ radius around a particular clinic. The population of each catchment area was estimated at the time of the baseline survey and a list of households was developed through mapping. Each provider catchment area was defined as a cluster based on population estimates of each provider area and a list of clusters was developed. The number of Married women of reproductive age (MWRA) respondents to be selected form each cluster was determined using probability proportional to size (PPS). Finally, households from within clusters (12 clusters in each study arm) were selected from the available sampling frame of households using a simple random sampling process. One MWRA was selected for interview in each household. For voucher clients a list was prepared. The total sample size required for voucher clients was distributed across each cluster based on PPS to calculate the number of voucher clients recruited in each cluster.

\section{Instrument}

A structured questionnaire was used that covered demographics, reproductive status, decision making and contraceptive status, quality of FP services, and poverty assessment. The questionnaire was translated from English into Urdu (national language of Pakistan) back translated, pre-tested and administered face-to-face by trained interviewers.

\section{Data analysis}

Data were analysed using descriptive, inferential and regression statistics. Chi-square and t-test were used to compare sample characteristics between intervention and control arms to assess the differences in categorical and continuous variables respectively. Binary response variables for logistic regression analysis were contraceptive awareness (any one method), ever use (any method), current use (any method), modern method (any modern method) and first time modern contraceptive use, each recorded in Yes vs No categories. Odds ratios represented the likelihood of contraceptive - awareness, -ever use, -current use, -modern method and first time modern contraceptive use.
Effectiveness of the intervention was measured in terms of increase in modern contraceptive use and reduction in inequality by wealth quintiles in the intervention arm compared to the control from baseline to endline.

Analysis was weighted to account for the effect of oversampling of voucher clients in intervention districts. Weights were assigned based on the distribution of each stratum in the intervention area. The total estimated MWRA population in the intervention areas was 30,591, while total voucher clients (VC) in the same survey areas was 7101 . The weights assigned to each stratum were 1) general population MWRA $(30591-7101=23,490) 23490 / 30591=0.767873$ and 2$)$ voucher clients 7101/30591 $=0.232127$.

To isolate the effect of the intervention, Differencein-Differences (DID) were estimated for key contraceptive variables. Statistical Package for Social Scientists (SPSS) version 22.0 was used for data analysis.

For the equity analysis, we used household wealth index scores generated through principal component analysis. Based on baseline and endine data, quintiles were developed where quintile 1 (Q1) indicated the poorest $20 \%$ of households and quintile 5 (Q5) represented the richest. We performed the slope index of inequality $[35,36]$, and two relative inequality indicators (the ratio of $\mathrm{Q} 5$ to $\mathrm{Q} 1$, and the concentration index). The main interpretation of absolute index of inequalities is the difference between the extreme wealth quintiles. The relative index of inequalities is based on a ratio. The slope index (SII) uses the coverage values in the difference in percentage points between individuals at the top and bottom of the wealth scale. We calculated the SII by regressing five outcomes against an individual's relative rank in the cumulative distribution of socioeconomic position. Concentration curves for each study area were generated to assess differences in horizontal equity over voucher client and general population. [35, 37]. Concentration index was also calculated ranging from -1 to 1 . The value of concentration index at 0 , indicates that there is no inequality i.e. access to health services (utilization of modern contraceptive methods) makes no difference among poor and rich population. The negative value indicates relatively higher utilization modern contraceptive use among the poor and vice versa. All analyses at both the univariate and multiple regression stages adjusted for the probability sample weights. Equity analyses were performed using Stata version 14.0 Software (StataCorp, College Station, Texas USA).

\section{Ethics approval and consent to participate}

All respondents were informed about the survey and their rights. No personal information was entered in the 
database that could be used to identify specific individuals. The study protocol was approved by National Bioethics Committee (NBC) Pakistan. Ref: No. 4-87/12/ NBC-92/RDC/3548 [8]. All survey participants provided a written informed consent.

\section{Results}

We recruited 1318 respondents from the intervention district, stratified into 390 voucher respondents and 928 respondents were from the general population. In the control district we recruited 1296 respondents from the general population.

\section{Demographic characteristics}

\section{Age structure and demographics}

The average age of participating women was around 31 years in intervention and 30 years in control areas with no significant change observed in both study arms between baseline and end line including the age of husband (for details see Table 2).

\section{Contraceptive uptake and awareness patterns Current contraceptive use}

Current use of any contraceptives has increased by 30 percentage points in intervention area. It increased from $21 \%$ at baseline to $51 \%$ at end line. In the control group women current use of any contraceptive at end line was $32 \%$ compared to $18 \%$ at baseline; a 14 percentage points increase at the endline (Table 3). Difference in difference analysis for contraceptive use shows the net effect for any contraceptive current user and modern method user was 16 and $26 \%$, respectively, which was significant.

Among methods, the most significant change was observed in IUD use, which increased by 18 percentage points at end line with a net effect of $16 \%$. The second most significant change in intervention areas was for condom use which increased by 6 percentage points.

\section{Ever use and contraceptive methods awareness}

Ever use of contraceptives increased significantly in project areas. In intervention areas the increase was $44 \%$ (baseline: $35 \%$, end line: $79 \%)(p=<0.0001)$ and in control areas the increase was up 33\% (baseline: $25 \%$, end line $58 \%)(p=<0.0001)$, with a net change of $11 \%$ (Table 3 ).

At end line, awareness of methods was significantly higher in both intervention and in control areas. In the intervention areas, compared to baseline, there was a significant change in awareness of three most common methods including Pills (55 to 67\%), Injections (52 to $59 \%$ ) and IUDs (43 to 60\%). (See in Table 4). Awareness of all contraceptive methods increased significantly in control areas.

\section{Method discontinuation and switching}

MWRA in intervention and control areas were inquired about contraceptive use, discontinuation and switching

Table 2 Demographic characteristics of participants

\begin{tabular}{|c|c|c|c|c|c|c|}
\hline & \multicolumn{3}{|l|}{ Chakwal } & \multicolumn{3}{|l|}{ Bhakkar } \\
\hline & Baseline $n=691$ & Endline $n=1318$ & $p$-value & Baseline $n=2585$ & Endline $n=1296$ & $p$-value \\
\hline & \multicolumn{3}{|l|}{ Mean \pm SD } & \multicolumn{3}{|l|}{ Mean \pm SD } \\
\hline Age of MWRA & $32 \pm 7.4$ & $31.4 \pm 6.3$ & 0.057 & $30 \pm 6.2$ & $30.0 \pm 6.6$ & 1 \\
\hline Age of husband & $37 \pm 8.6$ & $36.9 \pm 7.3$ & 0.784 & $34 \pm 7.5$ & $34.4 \pm 7.8$ & 0.123 \\
\hline Age of women at time of marriage & $20 \pm 3.7$ & $20.4 \pm 3.5$ & 0.017 & $20 \pm 3.3$ & $19.6 \pm 3.3$ & $<0.001$ \\
\hline Male members of household (a) & $3.3 \pm 1.8$ & $2.5 \pm 1.2$ & $<0.001$ & $3.1 \pm 1.7$ & $3.2 \pm 1.7$ & 0.085 \\
\hline Female members of household (b) & $3.3 \pm 1.8$ & $2.4 \pm 1.4$ & $<0.001$ & $3.1 \pm 1.8$ & $3.1 \pm 1.8$ & 1 \\
\hline Average household size & $6.5 \pm 3.1$ & $4.9 \pm 2.1$ & $<0.001$ & $6.2 \pm 2.9$ & $6.3 \pm 2.8$ & 0.308 \\
\hline Husband is the Head of Household & 80.0 & 92.0 & $<0.0001$ & 87.0 & 75.0 & $<0.001$ \\
\hline \multicolumn{7}{|l|}{ Literacy level (\%) } \\
\hline Illiterate & $32 \%$ & $11.5 \%$ & $<0.001$ & $63 \%$ & $45.7 \%$ & $<0.001$ \\
\hline Can read, write and perform simple sums & $6 \%$ & $4.2 \%$ & 0.044 & $7 \%$ & $4.4 \%$ & 0.0002 \\
\hline Primary ( 1 to 5$)$ & $19 \%$ & $23.9 \%$ & 0.0105 & $15 \%$ & $23.8 \%$ & $<0.0001$ \\
\hline Middle (6 to 8 ) & $8 \%$ & $18.2 \%$ & $<0.0001$ & $5 \%$ & $9.4 \%$ & $<0.0001$ \\
\hline Matriculation & $20 \%$ & $28.2 \%$ & $<0.0001$ & $8 \%$ & $9.7 \%$ & 0.0368 \\
\hline Intermediate & $6 \%$ & $8.2 \%$ & 0.1019 & $2 \%$ & $2.5 \%$ & 0.0517 \\
\hline Graduate/postgraduate & $8 \%$ & $5.7 \%$ & 0.0883 & $4 \%$ & $4.4 \%$ & 1 \\
\hline
\end{tabular}

Numbers are means and percentages unless otherwise specified

(a) Missing at endline Chakwal =1, Bhakkar =1, (b) baseline Chakwal =1, (c) missing endline Chakwal 16, Bhakkar 2 
Table 3 Difference in difference analysis for ever use, current contraceptive use by type and method

\begin{tabular}{|c|c|c|c|c|c|c|c|}
\hline & Control & & Intervention & & Absolute & ce (\% change)+ & Net effect (\% change)^ \\
\hline & Baseline (\%) & Endline (\%) & Baseline (\%) & Endline (\%) & Control & Intervention & \\
\hline Ever user & 25 & 58 & 35 & 79 & 33 & 44 & $11^{* * *}$ \\
\hline Current user ${ }^{1}$ & 18 & 32 & 21 & 51 & 14 & 30 & $16^{* * *}$ \\
\hline Modern Method ${ }^{2}$ & 16 & 22 & 19 & 50 & 6 & 32 & $26^{* * *}$ \\
\hline Pill & 2 & 1 & 2 & 3 & -1 & 1 & 2 \\
\hline $\mathrm{IUD}^{\mathrm{a}}$ & 2 & 4 & 2 & 20 & 2 & 18 & $16^{* * *}$ \\
\hline Injections & 2 & 2 & 3 & 4 & 0 & 1 & 1 \\
\hline Implants & & 0 & & 2 & 0 & 2 & 2 \\
\hline Condom & 7 & 9 & 7 & 13 & 2 & 6 & $4^{*}$ \\
\hline Female sterilization & 3 & 6 & 5 & 8 & 3 & 3 & 0 \\
\hline Traditional Method ${ }^{3}$ & 2 & 10 & 1 & 1 & 8 & 0 & $-8^{* * * *}$ \\
\hline Periodic Abstinence & 2 & 1 & 0 & 0 & -1 & 0 & 1 \\
\hline Withdrawal & 0 & 3 & 1 & 0 & 3 & -1 & $-4^{* * *}$ \\
\hline LAM $^{b}$ & 0 & 6 & 0 & 1 & 6 & 1 & $-5^{* * *}$ \\
\hline
\end{tabular}

$P$-value: ${ }^{* *} p<0.01 ;{ }^{* *} p<0.05 ;{ }^{*} p<0.1$

+ Absolute difference is the percentage change from baseline to endline

$\wedge$ Net effect is the percentage change in intervention group subtracting the percentage change in control group

${ }^{\mathrm{a}}$ Intra uterine device ${ }^{\mathrm{b}}$ Lactational amenorrhea method

${ }_{1}$ Percentage totals $\%$ for $2+3$

during the last 2 years. In Intervention district 842 women reported using a modern contraceptive method during the past 24 months. Out of these $13.7 \%$ reported discontinuing modern contraceptive use while $46.6 \%$ had switched to a modern contraceptive during the same time period. In Control district 354 women reported using a modern contraceptive method during the past 24 months. Women discontinuing modern contraceptive use in the control areas were two fold greater at $26.8 \%$ and only $13.3 \%$ had switched to using a modern method during the same time (see Table 5).
The most common methods discontinued were condoms, both in the intervention (57\%) and in control (58\%) areas, followed by IUD 17 and 18\% in intervention and control areas respectively (see Table 5).

Women in the intervention and control areas mainly discontinued due to a desire for more children (Intervention: $81 \%$, Control: $69 \%$ ) followed by health concerns (Intervention: $13 \%$, Control: 17\%). Women who reported switching to a modern method during the last 24 months were also asked about which method they switched to. The most common methods women switched to were IUDs (50\%)

Table 4 Awareness about contraceptives, overall and method specific

\begin{tabular}{|c|c|c|c|c|c|c|}
\hline & \multicolumn{3}{|l|}{ Intervention } & \multicolumn{3}{|l|}{ Control } \\
\hline & Baseline $n=694$ & Endline $n=1318$ & $p$-value & Baseline $n=2582$ & Endline $n=1296$ & $p$-value \\
\hline & $\%$ & $\%$ & & $\%$ & $\%$ & \\
\hline Awareness of any one method & 63 & 93 & 0.0001 & 56 & 97 & 0.0001 \\
\hline Pills & 55 & 67 & $<0.0001$ & 49 & 93 & $<0.0001$ \\
\hline IUD & 43 & 60 & $<0.0001$ & 35 & 76 & $<0.0001$ \\
\hline Injection & 52 & 59 & 0.0026 & 44 & 91 & $<0.0001$ \\
\hline Implant & 18 & 27 & $<0.0001$ & 10 & 23 & $<0.0001$ \\
\hline Condom & 44 & 65 & $<0.0001$ & 34 & 84 & $<0.0001$ \\
\hline Female Sterilization & 36 & 28 & 0.0002 & 22 & 69 & $<0.0001$ \\
\hline Male sterilization & 22 & 6 & $<0.0001$ & 13 & 18 & 0.0011 \\
\hline Emergency contraception & - & 11 & & - & 8 & \\
\hline Periodic abstinence & 31 & 26 & 0.0561 & 36 & 16 & $<0.0001$ \\
\hline Lactational amenorrhea method (LAM) & - & 78 & & - & 64 & \\
\hline Withdrawal & 32 & 14 & $<0.0001$ & 12 & 27 & $<0.0001$ \\
\hline
\end{tabular}

Multiple responses 
Table 5 Modern contraceptive use, discontinuation and switching during the last two years, measured at endline

\begin{tabular}{lll}
\hline & Intervention & Control \\
\hline Respondents reporting using modern & $n=842$ & $n=354$ \\
method in last 24 months & $n(\%)$ & $n(\%)$ \\
a) Discontinuation (number of & $115(13.7)$ & $95(26.8)$ \\
episodes) & $n=115$ & $n=95$ \\
Method discontinued & $n(\%)$ & $n(\%)$ \\
& $9(8)$ & $9(9)$ \\
Pills & $20(17)$ & $17(18)$ \\
IUD & $14(12)$ & $13(14)$ \\
Injection & $6(5)$ & - \\
Implant & $65(57)$ & $55(58)$ \\
Condom & $1(1)$ & $1(1)$ \\
Diaphragm & $392(46.6)$ & $47(13.3)$ \\
b) Switching to other modern & & \\
method & $n=392$ & $n=47$ \\
Switched to different method & $n(\%)$ & $n(\%)$ \\
& $7(2)$ & $7(15)$ \\
Female sterilization & $195(50)$ & $3(6)$ \\
IUD & $37(9)$ & $13(28)$ \\
Injectable & $21(5)$ & $1(2)$ \\
Implants & $22(6)$ & $6(13)$ \\
Pills & $108(28)$ & $16(34)$ \\
Others & 2 & 1 \\
\hline
\end{tabular}

${ }^{\mathrm{a}}$ Others = diaphragm and male sterilization

and condoms $(28 \%)$ in intervention areas, while women in control areas most commonly switched to condoms (34\%) followed by injectable contraceptives (28\%).

\section{Targeting voucher clients}

The distribution of voucher clients according to adapted poverty assessment tool indicates that $31 \%$ of the voucher clients fulfilled the poverty assessment criteria based on the tool [34]. Almost all $(99,2 \%)$ of the voucher clients were FP method users. The two main FP methods used by voucher clients were IUD (56\%) followed by condoms (14\%).

Respondents in intervention areas were 1.8 (95\% CI: 1.4-2.2), 1.7 (95\% CI: $1.3-2.2$ ) and 2.2 (95\% CI: $1.7-2.8)$ times more likely to ever use any contraceptive method, currently use any contraceptive method and modern methods respectively as compared to respondents in the control group, adjusting for other variables in the model. Women in the 'poorest' socioeconomic quintile were more likely to be ever contraceptive users OR: 1.7 (95\% CI: 1.2-2.4), current contraceptive users OR: 1.7 (95\% CI: 1.1-2.5) and modern contraceptive users OR: 1.7 (95\% CI: 1.1-2.6), compared to women in the richest quintile while adjusting for other variables in the model.,,. Women in the 'poor' socioeconomic quintile more likely to be ever contraceptive users OR: 1.6 (95\% CI: $1.23-$ 2.04), current contraceptive users OR: 1.4 (95\% CI: $1.02-$ 1.9), and modern contraceptive users OR: 1.4 (95\% CI: 1.01.9), compared to women in the richest quintile while adjusting for other variables in the model (see Table 6).

\section{Equity analysis}

Overall mean coverage of all contraception variables including awareness, ever use, current use, modern method and first time use were substantially higher in intervention group than control group.

\section{Utilization of contraceptive methods}

The summary of equity indices in intervention area is shown below in Table 7.

Table 7 presents the use of contraceptive methods and maternal health services by women in the poorest and the richest quintile, based on baseline and endline data. The table also includes summary equity indices. The percentage difference (SII) of contraceptive ever use from poorest-to-richest was - $23 \%$ in intervention groups, indicating that women in the richest quintile were $23 \%$ less likely to ever use a contraceptive (Table 7).

The poorest-richest difference (SII) for current contraceptive use was $-19 \%$ in intervention areas, followed by - $18 \%$ poorest-richest difference (SII) for modern method use. Both these findings suggest that women in the richest quintiles were less likely to be current contraceptive users and modern contraceptive users respectively (Table 7).

Concentration index for awareness, modern method, and current use of contraception found negative values in intervention areas, indicating that the use of these indicators were more concentrated among the disadvantaged (poor).

\section{Concentration curves and index}

The concentration curves plot the cumulative proportion of modern contraceptives use against wealth status for intervention and control areas. The concentration curves and indices for MSS project area are presented in the below Fig. 2 .

Figure Notes: Concentration index, - 0.011 (95\% CI, $0.030-0.008 ; p=0.24)$ for voucher client and -0.030 (95\% CI, $-0.071-0.012 ; p=0.16)$ for general population in the intervention arm at endline.

Concentration curves for utilization of modern contraceptive methods among voucher client and non-voucher client (general population) both lie above the line of equality, indicating a disproportionately higher concentration of modern contraceptive method use in poor 
Table 6 Logistic regression models identifying factors associated with contraceptive awareness and use among the socioeconomic quintiles (baseline and endline)

\begin{tabular}{|c|c|c|c|c|c|}
\hline \multirow[t]{2}{*}{ Characteristics } & $\begin{array}{l}\text { Contraceptive awareness any one } \\
\text { method }\end{array}$ & Ever use (any method) & Current use (any method) & Modern method use & $\begin{array}{l}\text { First time modern } \\
\text { contraceptive use }\end{array}$ \\
\hline & \multicolumn{5}{|l|}{ Odds ratio ( $95 \%$ Confidence interval) } \\
\hline \multicolumn{6}{|l|}{ Study area } \\
\hline Intervention & $0.72(0.45-1.17)$ & $1.8(1.44-2.24)$ & $1.68(1.31-2.16)$ & $2.18(1.67-2.84)$ & $0.87(0.49-1.56)$ \\
\hline Control & 1.00 & 1.00 & 1.00 & 1.00 & 1.00 \\
\hline Household size & $1.02(0.99-1.06)$ & $1.07(1.03-1.11)$ & $1.07(1.03-1.10)$ & $1.07(1.04-1.11)$ & $0.98(0.92-1.04)$ \\
\hline \multicolumn{6}{|l|}{ Wealth quintile } \\
\hline Poorest & $1.78(1.06-2.97)$ & $1.68(1.16-2.42)$ & $1.67(1.13-2.46)$ & $1.69(1.13-2.55)$ & $0.56(0.27-1.19)$ \\
\hline Poor & $1.26(0.89-1.79)$ & $1.58(1.23-2.04)$ & $1.37(1.02-1.85)$ & $1.39(1.00-1.94)$ & $0.62(0.27-1.43)$ \\
\hline Average & $1.27(0.90-1.81)$ & $1.29(1.03-1.62)$ & $1.29(0.95-1.75)$ & $1.29(0.93-1.80)$ & $0.61(0.25-1.47)$ \\
\hline Rich & $0.97(0.76-1.24)$ & $0.96(0.77-1.20)$ & $0.98(0.76-1.27)$ & $0.94(0.68-1.29)$ & $0.48(0.21-1.08)$ \\
\hline Richest & 1.00 & 1.00 & 1.00 & 1.00 & 1.00 \\
\hline
\end{tabular}

Adjusted for respondent's age, husband's age, respondent's education, and husband's education, household size, baseline and end line survey points

population than in rich ones. However, the degree of inequality among voucher client was quite lower than general population, since the concentration curve for the voucher client lies almost closer to the equality line. For the general population, most part the concentration curves were far above the line of equality, depicting utilization of modern contraceptive methods was more pro-poor. These findings indicate that the general population in lower income have a greater proportion of modern contraceptive use than those with higher income. The concentration index for utilization of modern contraceptive use decreased from - 0.030 (95\% CI, $0.071-0.012 ; p=0.16)$ in general population area to 0.011 (95\% CI, $-0.030-0.008 ; p=0.24)$ in voucher client area.

\section{Discussion}

Vouchers can be a highly effective tool to increase access to and use of family planning and reproductive health services, especially for underserved populations including the poor, youth, and postpartum women [25]. The experience in Pakistan shows that vouchers can facilitate access to modern contraceptive services where supply-side approaches don't work. In line with other studies, the results of this study also confirmed that when vouchers are targeted towards poor beneficiaries who otherwise would not capitalise on a service - they are particularly effective at improving equity $[25,26]$. Voucher programmes improve access to institutional delivery, as shown by a Cambodian voucher scheme. It has been associated with an increase of 10 percentage points in the probability of institutional

Table 7 Magnitude of inequalities in contraceptive services use in the intervention areas (baseline and endline)

\begin{tabular}{|c|c|c|c|c|c|c|}
\hline \multirow[t]{2}{*}{ Characteristics } & \multirow[b]{2}{*}{ Overall } & \multicolumn{2}{|l|}{ Coverage, (\%) } & \multicolumn{3}{|l|}{ Inequality assessment } \\
\hline & & Q1 (Poorest) & Q5 (Richest) & SII (Q5: Q1, \% points) & RII (Q5:Q1) & Concentration index $(\times 100)$ \\
\hline \multicolumn{7}{|l|}{ Intervention areas } \\
\hline Ever use & $58.5(56.6-60.4)$ & $63.4(60.1-66.8)$ & $27.9(19.7-36.1)$ & $-23.3(-32.4--14.2)$ & $0.4(0.2-0.6)$ & $-1.6(-3.2--0.05)$ \\
\hline Current user & $37.4(35.4-39.4)$ & $42.1(38.2-45.9)$ & $14.8(9.6-20.0)$ & $-18.8(-25.5--12.2)$ & $0.5(0.3-0.7)$ & $-0.1(-2.6-2.4)$ \\
\hline Modern method user & $35.9(33.9-37.8)$ & $40.4(36.7-44.2)$ & $14.3(9.5-19.2)$ & $-17.5(-23.8--11.2)$ & $0.3(0.2-0.6)$ & $-0.04(-0.8-0.7)$ \\
\hline First time use $\mathrm{a}^{(\mathrm{a})}$ & $68.8(65.5-72.1)$ & $73.7(68.3-79.0)$ & $78.1(55.5-100.0)$ & $4.4(-18.8-27.7)$ & $1.2(0.4-3.7)$ & $-2.3(-5.4-0.7)$ \\
\hline Awareness & $82.6(81.1-84.1)$ & $88.3(85.9-90.7)$ & $54.2(45.1-63.2)$ & $-25.5(-33.1--18.0)$ & $0.2(0.1-0.4)$ & $-2.7(-3.8--1.6)$ \\
\hline \multicolumn{7}{|l|}{ Control areas } \\
\hline Ever use & $36.1(34.7-37.5)$ & $39.3(35.5-43.2)$ & $35.6(32.9-38.3)$ & $-12.8(-17.5--8.1)$ & $0.5(0.4-0.7)$ & $-6.9(-9.2--4.6)$ \\
\hline Current user & $22.3(21.0-23.6)$ & $26.9(23.2-30.5)$ & $21.6(19.2-24.0)$ & $-9.3(-13.7--5.0)$ & $0.7(0.6-0.8)$ & $-7.0(-10.4--3.5)$ \\
\hline Modern method user & $17.7(16.5-18.9)$ & $22.7(19.2-26.1)$ & $17.2(14.9-19.4)$ & $-7.4(-11.6--3.2)$ & $0.6(0.5-0.8)$ & $0.7(0.3-1.1)$ \\
\hline First time use $\mathrm{a}^{(\mathrm{a})}$ & $76.2(71.2-81.1)$ & $67.6(51.9-83.4)$ & $82.6(75.7-89.5)$ & $15.0(-2.2-32.1)$ & $2.3(1.0-5.4)$ & $5.3(1.8-9.0)$ \\
\hline Awareness & $70.0(68.7-71.3)$ & $77.2(73.9-80.6)$ & $66.9(64.6-69.2)$ & $-22.1(-26.3--17.9)$ & $0.2(0.1-0.4)$ & $-6.2(-7.3--5.1)$ \\
\hline
\end{tabular}

SII Slope index inequality, RII Relative index inequality; $95 \% \mathrm{Cl}, 95 \%$ Confidence interval, ${ }^{(a)}$ First time contraceptive use; All equity analysis were adjusted for baseline and end line survey point 


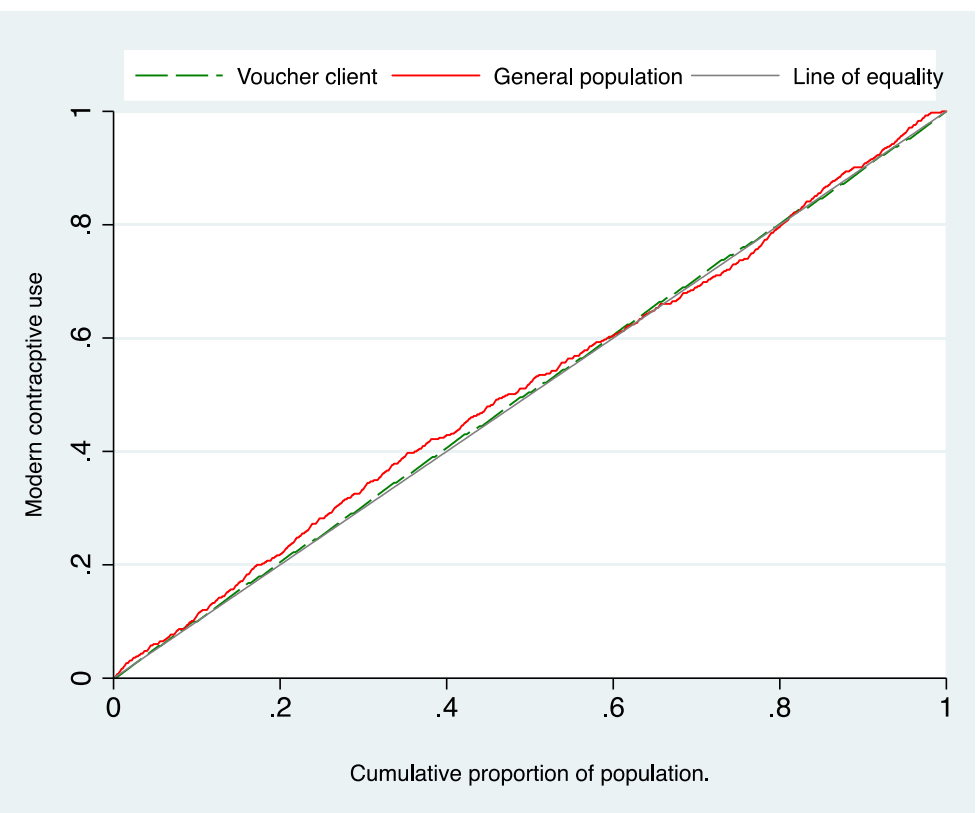

Fig. 2 Concentration curve of modern contraceptive use by voucher client and general population

delivery, and among the poorest $40 \%$ of households, the increase in the prevalence of the probability of child birth in a public health-care facility was 15.6 percentage points [38], similar results were shown in a study in Kenya [19] and Bangladesh and Pakistan [10,28].

The World Health Organization (WHO) has suggested that, in order to overcome the lack of contraceptive services in developing regions of the world, the implementation of contracting out, social franchising and voucher schemes are of value [39-41]. The study findings also corroborate with earlier studies in Pakistan [10-12], where it was promising to note an increase in $26 \%$ net percentage points for modern contraceptives in intervention areas and an increase of $18 \%$ point in IUD use was also noted. The approach adopted in this study is perhaps resource-intensive in terms of human and financial resources, but it has been effective in increasing IUD uptake among underserved segments of the population, whereas in comparison the national figures record a very low prevalence.

Targeting has always posed challenges for any health intervention $[39,40]$. The findings from our study demonstrated that as intended, the respondents in intervention areas had low education levels, and further analysis also noted that users in the lowest two quintiles were more likely to use them than their affluent counterparts $[2,39]$. The findings of this study concur with the earlier findings where, compared to the control area, the discontinuation rates for modern contraceptives decreased and increase in switching pattern was noted in the intervention areas [11, 12]. However, contraceptive use in control areas also recorded an increase. This finding in itself has important implications for policy formulation. Given that secular trends in Pakistan show that contraceptive usage is increasing, the question is whether it is increasing at a sufficient magnitude and at a reasonable enough speed in order to achieve FP2020 targets for the country.

According to a national survey in Pakistan, contraceptive discontinuation rates in Pakistan stand at 37\% within the first 12 months of use [2]. Furthermore, reported major reasons for discontinuation were side effects or health concerns, followed by the desire to become pregnant and method failure. In addition, out of the total method discontinuations, $80 \%$ did not switch to another method of contraception. The same national survey also recorded an overall discontinuation rate of $26 \%$ for LARC and for IUD, within 12 months of use due to any reason. Out of these, 2/3rd of the women who had their IUDs removed did not switch to another method. Findings from our study suggests that the intervention areas were successful in keeping modern-method discontinuation low at $13.7 \%$ compared to control areas where modern method discontinuation was almost twice as high, at $26.9 \%$, during the 24 months preceding the survey. This reported low modern-method discontinuation rate is way better than the current national estimates and from the other demand-side financing studies from Pakistan using vouchers $[2,39,42-44]$. Apart from the favourable impact on the continuation of modern contraceptive use, the intervention was also instrumental in enhancing modern-method use in terms of the greater 
percentage of women (46.6\%) compared to $13.3 \%$ of women from control areas who switched to a modern contraceptive during the same time period. This finding suggests that the intervention has been useful in promoting continuous use of modern contraceptive methods.

Equity implies that those in need have access to health services and use them. Ensuring reliable and actionable measures of health equity is especially important for managers and other implementers in global health who aim to target the poor [45-47]. Health equity measures indicated that current use and modern method use of contraception was significantly higher in poorest group in study areas than their richest counterparts, implying that vouchers increased access and use of contraceptives among the poor. The concentration curves among voucher clients curve were closer to the perfect equality line than general population curve and the concentration index decreased implying that voucher intervention has a positive impact in reducing the inequality gap between poor and rich for the use of modern contractive methods.

The key limitations of our research are mostly related to quasi experimental study design and generalizability of the findings. However, we have ensured a control and intervention area for comparison. The study captured views of women and did not include men's perspectives. Thus the results need to be interpreted with caution. The quasi-interventional studies present some limitations such as in controlling for some confounding variables, due to non-randomization. However, such designs are recognised for use in situations where controlled trials are not feasible due to logistical, financial or other ethical reasons. Furthermore, in order to avoid any spill over effects, we chose control and intervention areas at a distance from each other. Therefore, we are confident that the increase in the outcomes of our study is attributed to the study intervention.

\section{Conclusion}

The findings from this study suggest that the DSF approach of free voucher provision through a SF model is effective in promoting family planning, especially through long-term contraceptive methods such as IUDs. The government should consider adopting a similar approach whereby private sector service providers in the community are trained to provide family planning services through vouchers in combination with a social franchising approach depending on available resources or funding. The desirability of this approach presents some advantages.

First, the model enables widespread access to costly, long-term family planning services. The public sector can use this model to increase the reach of their services. Second, the role of community mid-level service providers in enhancing contraceptive use is highlighted as other studies concur that they can be more effective and acceptable being part of the local community. [11, 18, 24, 43, 44]. In the Pakistani context, where health-seeking needs of women is ancillary to those of male family members, the provision of quality family planning services within the community curtails the need for the women to go to distant health facilities. Lastly, engaging public sector using vouchers to reach the poor and deserving especially in rural settings with quality services will reduce the risk of women having to seek the services from unskilled providers that would increase the medical risk of morbidity and mortality.

Scaling up of voucher delivery is instrumental to FP intervention programmes that have the potential to reduce fertility levels in line with the goals set by the United Nations (UN) Sustainable Development Goals (SDGs) and Universal Health Coverage aiming to reduce global poverty $[48,49]$. Findings from this study bridge the knowledge gap on effectiveness of voucher interventions that are more useful in furthering SDGs in low and middle income countries and also cater to the needs of women in family planning by subsequently decreasing the burden of morbidity and mortality resulting from unplanned and untimely pregnancies.

In future, researchers are encouraged to study the aspects of sustainability in capturing the follow-up behaviour and practices such as method continuation in the absence of voucher intervention. This information may fill in knowledge gaps regarding future scalability and sustainability of voucher programmes.

\section{Abbreviations \\ DID: Difference-in-Differences; DSF: Demand Side Financing; FP: Family Planning; IEC: Information-Education-Communication; IUD: Intrauterine Device; LARC: Long Acting Reversible Contraceptive; mCPR: Modern \\ Contraceptive Prevalence Rate; MSI: Marie Stopes International; MSS: Marie Stopes Society; MWRA: Married Women of Reproductive Age; PPS: Probability Proportional to Size; WHO: World Health Organization}

\section{Acknowledgements \\ Authors are highly indebted to all the enumerators, field workers; and above all, to the study participants for their time and for enriching this study by sharing their experiences. \\ Funding \\ The research project was funded by The David and Lucile Packard Foundation, this evaluation is conducted independently by the Department of Reproductive Health and Research, World Health Organization, Geneva. There was no role of the funding organization in the design of the study and collection, analysis, and interpretation of data and in writing the manuscript.}

\section{Availability of data and materials}

The data will be available upon request as per the WHO policies. Requests for access to data can be sent to alimoa@who.int

\section{Authors contributions}

This evaluation was conceptualized and conducted by MA, SKA, HBH and MMR independently, without any consultation with the project implementing organization i.e. MSS/MSI. MA, SKA, HBH and MMR developed 
the first and final drafts of the manuscript. WH provided intellectual contribution to the final draft of the manuscript. All authors have read and approved the manuscript, and ensure that this is the final version.

\section{Ethics approval and consent to participate}

All respondents were informed about survey and their rights. No personal information was entered in the database that could be used to identify specific individual. The study protocol was approved by National Bioethics Committee (NBC) Pakistan. Ref: No. 4-87/12/NBC-92/RDC/3548 [8] All survey participants provided a written informed consent to participate in the survey. This study does not fall within the International Committee of Medical Journal Editors (ICMJE)' definition of a clinical trial.

\section{Consent for publication}

Not Applicable.

\section{Competing interests}

The authors declare that they have no competing interests.

\section{Publisher's Note}

Springer Nature remains neutral with regard to jurisdictional claims in published maps and institutional affiliations.

\section{Author details}

'Department of Reproductive Health and Research, World Health Organization, Avenue Appia 20, CH-1211 Geneva 27, Switzerland. ${ }^{2}$ Division of Health Information Systems, Hospital for Sick Children, Toronto, Canada. ${ }^{3}$ Department of Uro-gynecology, University of Ghent, Ghent, Belgium. ${ }^{4}$ Health Policy, System Strengthening and Information Analysis Unit, Ministry of National Health Services, Regulations and Coordination, Islamabad, Pakistan. ${ }^{5}$ Department of Global Health Policy, School of International Health, The University of Tokyo, Tokyo, Japan. ${ }^{6}$ Department of Research, Monitoring and Evaluation, Marie Stopes Society, Karachi, Pakistan.

Received: 9 February 2018 Accepted: 20 March 2019

Published online: 29 March 2019

\section{References}

1. World Health Organization. Country Cooperation Strategy - at a glance. Islamabad, Pakistan: WHO, 2013 [cited May 2016]. Available from: http:// www.who.int/countryfocus/cooperation_strategy/ccsbrief_pak_en.pdf. Accessed 23 Mar 2019.

2. National Institute of Population Studies, Macro International Inc. Pakistan Demographic and Health Survey 2012-13. Islamabad: Government of Pakistan, 2013. [cited November 15, 2015]. Available from: https:// dhsprogram.com/pubs/pdf/fr290/fr290.pdf. Accessed 23 Mar 2019.

3. Wulifan JK, Brenner S, Jahn A, De Allegri M. A scoping review on determinants of unmet need for family planning among women of reproductive age in low and middle income countries. BMC Womens Health 2016 Jan 15;16:2. PubMed PMID: 26772591. Pubmed Central PMCID: 4714507.

4. Azmat SK. Models to accelerate modern family planning/contraceptive services access and uptake among married women in rural Pakistan [doctoral research]. Ghent: Ghent University; 2017 [cited January 25, 2017] Available from: http://icrhb.org/sites/default/files/ FINAL\%20THESIS\%209\%20JAN\%202017.pdf. Accessed 23 Mar 2019.

5. National Institute of Population Studies P, Macro International I. Pakistan Demographic and Health Survey 1990-91. Islamabad: Government of Pakistan, 1992. [cited November 15, 2015]. Available from: https://www. dhsprogram.com/pubs/pdf/FR29/FR29.pdf. Accessed 23 Mar 2019.

6. National Institute of Population Studies P, Macro International I. Pakistan Demographic and Health Survey 2006-7. Islamabad: Government of Pakistan, 2008. [cited November 15, 2015]. Available from: https:// dhsprogram.com/pubs/pdf/FR200/FR200.pdf. Accessed 23 Mar 2019.

7. Ali M, Seuc A, Rahimi A, Festin M, Temmerman M. A global research agenda for family planning: results of an exercise for setting research priorities. Bulletin of World Health Organization 2014 Feb 1:92(2):93-98. PubMed PMID: 24623902. Pubmed Central PMCID: 3949533.

8. Azmat SK, Ali M, Hameed W, Mustafa G, Abbas G, Ishaque M, et al. A study protocol: using demand-side financing to meet the birth spacing needs of the underserved in Punjab Province in Pakistan. Reprod Health 2014;11:39. PubMed PMID: 24885657. Pubmed Central PMCID: PMC4059733.

9. Murray SF, Hunter BM, Bisht R, Ensor T, Bick D. Effects of demand-side financing on utilisation, experiences and outcomes of maternity care in low- and middleincome countries: a systematic review. BMC pregnancy and childbirth 2014;14:30. PubMed PMID: 24438560. Pubmed Central PMCID: 3897964.

10. Agha S. Impact of a maternal health voucher scheme on institutional delivery among low income women in Pakistan. Reprod Health 2011;8:10. PubMed PMID: 21539744. Pubmed Central PMCID: 3108911.

11. Azmat SK, Hameed W, Hamza HB, Mustafa G, Ishaque M, Abbas G, et al. Engaging with community-based public and private mid-level providers for promoting the use of modern contraceptive methods in rural Pakistan: results from two innovative birth spacing interventions. Reprod Health 2016; 13(25):1-15. Pubmed Central PMCID: PMC4797360. Epub March 17, 2016.

12. Azmat SK, Shaikh BT, Hameed W, Mustafa G, Hussain W, Asghar J, et al. Impact of social franchising on contraceptive use when complemented by vouchers: a quasi-interventional study in rural Pakistan. PLoS One 2013;8(9): e74260. PubMed PMID: 24069287. Pubmed Central PMCID: 3772094.

13. Azmat SK, Shaikh BT, Hameed W, Bilgrami M, Mustafa G, Ali M, et al. Rates of IUCD discontinuation and its associated factors among the clients of a social franchising network in Pakistan. BMC Womens Health. 2012;12(1):8.

14. Bajracharya A, Bellows B, Dingle A. Evaluation of a voucher programme in reducing inequities in maternal health utilisation in Cambodia: a quasiinterventional study. Lancet. 2013;381:S12.

15. Bellows B, Bulaya C, Inambwae S, Lissner CL, Ali M, Bajracharya A. Family planning vouchers in low and middle income countries: a systematic review. Stud Fam Plan 2016 Dec;47(4):357-370. PubMed PMID: 27859338. Pubmed Central PMCID: 5434952.

16. Bellows BW, Conlon CM, Higgs ES, Townsend JW, Nahed MG, Cavanaugh K, et al. A taxonomy and results from a comprehensive review of 28 maternal health voucher programmes. J Health Popul Nutr 2013;31(4 Suppl 2):106128. PubMed PMID: 24992806.

17. Jones GW. Population situation analysis for Pakistan [Internet]. IslamabadPakistan: United Nations Population Fund, 2016.[cited May 2017] Available from: http://ec2-54-210-230-186.compute-1.amazonaws.com/wp-content/ uploads/2017/03/PSA-Printed-Report-1.pdf. Accessed 23 Mar 2019.

18. Munroe E, Hayes B, Taft J. Private-sector social franchising to accelerate family planning access, choice, and quality: results from Marie stopes international. Global health, science and practice 2015;3(2):195-208. PubMed PMID: 26085018. Pubmed Central PMCID: 4476859.

19. Obare F, Warren C, Abuya T, Askew I, Bellows B. Assessing the populationlevel impact of vouchers on access to health facility delivery for women in Kenya. Soc Sci Med 2014 Feb;102:183-189. PubMed PMID: 24565156.

20. Belaid L, Dumont A, Chaillet N, Zertal A, De Brouwere V, Hounton S, et al. Effectiveness of demand generation interventions on use of modern contraceptives in low- and middle-income countries. Tropical Medicine \& International Health. 2016 Jul 27. PubMed PMID: 27465589.

21. Nishtar S, Boerma T, Amjad S, Alam AY, Khalid F, Haq I, et al. Pakistan's health system: performance and prospects after the 18th constitutional amendment. Lancet. 2013;381(9884):2193-206.

22. United Nations Foundation. Family Planning 2020 Washington, DC: United Nations Foundation; 2016 [cited 201610 September]. Available from: http:// www.familyplanning2020.org/. Accessed 23 Mar 2019.

23. Lissner $\mathrm{CL}$, Ali M. Systematic reviews of mechanisms for financing family planning: findings, implications, and future agenda. Stud Fam Plan 2016 Dec;47(4):295-308. PubMed PMID: 27925673.

24. Boddam-Whetham L, Gul X, Al-Kobati E, Gorter AC. Vouchers in fragile states: reducing barriers to long-acting reversible contraception in Yemen and Pakistan. Global health, science and practice. 2016 Aug 11;4 Suppl 2: S94-S108. PubMed PMID: 27540129. Pubmed Central PMCID: 4990166.

25. Menotti EP, Farrell M. Vouchers: a hot ticket for reaching the poor and other special groups with voluntary family planning services. Glob Health Sci Pract. 2016;4(3):384-93 https://doi.org/10.9745/GHSP-D-16-00084.

26. Bellows B, Menotti E, Malarcher S. Vouchers: addressing inequities in access to contraceptive services. Washington D.C.: USAID, 2015. [cited December 21, 2016]. Available from: https://www.fphighimpactpractices.org/briefs/ vouchers/. Accessed 23 Mar 2019.

27. Bellows NM, Bellows BW, Warren C. Systematic review: the use of vouchers for reproductive health services in developing countries: systematic review. Tropical medicine \& international health : TM \& IH 2011 Jan;16(1):84-96. PubMed PMID: 21044235. 
28. Gorter AC, Ir P, Meessen B. Evidence Review, Results-Based Financing of Maternal and Newborn Health Care in Low- and Lower-middle-Income Countries. German Federal Ministry for Economic Cooperation and Development (BMZ) through the sector project PROFILE at GIZ Deutsche Gesellschaft für Internationale Zusammenarbeit, in cooperation with KfW, 2013. [cited October 23, 2016]. Available from: https://www.oecd.org/dac/peer-reviews/Evidence-RBF-maternal-health. pdf. Accessed 23 Mar 2019.

29. Janowitz B, Stanback J, Boyer B. Task sharing in family planning. Stud Fam Plan 2012 Mar;43(1):57-62. PubMed PMID: 23185872.

30. Marie Stopes International. Task sharing: Increasing access to family planning [Brief]. London, UK: MSI; 2013. [cited September 20, 2016]. Available from: https://www.k4health.org/sites/default/files/MSI. TaskSharing2Pager.pdf. Accessed 23 Mar 2019.

31. Azmat SK, Mustafa G, Hameed W, Asghar J, Ahmed A, Shaikh BT. Social franchising and vouchers to promote long-term methods of family planning in rural Pakistan: a qualitative stocktaking with stakeholders. Journal of Pakistan Medical Association 2013 Apr;63(4 Suppl 3):S46-S53. PubMed PMID: 24386730.

32. Ali M, Azmat SK, Hamza HB. Assessment of the effectiveness of a demand side financing voucher schemes in meeting birth spacing needs of the underserved in Punjab, Pakistan. International Conference on Family Planning Nusa Dua, Bali.2016. [cited February 10, 2016]. Available from: http://fpconference.org/2016/. Accessed 23 Mar 2019.

33. UNICEF. Multiple indicator cluster survey (2007-2008). Islamabad: UNICEF, 2007-08 [cited July 2017] Available from: http://www.bos.gop.pk/ mics20072008. Accessed 23 Mar 2019.

34. Schreiner M. Progress out of Poverty Index (PPI) for Pakistan Washington D. C.: Grameen Foundation; 2009 [cited 2015 September 15]. Available from: https://journals.sagepub.com/doi/10.1177/0021909609353579. Accessed 23 Mar 2019.

35. World Health Organization. Handbook on health inequality monitoring: with a special focus on low- and middle-income countries. Geneva: World Health Organization, 2013 [cited October 10, 2016]. Available from: http://apps.who. int/iris/handle/10665/85345. Accessed 23 Mar 2019.

36. Mackenbach JP, Kunst AE. Measuring the magnitude of socio-economic inequalities in health: an overview of available measures illustrated with two examples from Europe. Soc Sci Med 1997 Mar;44(6):757-771. PubMed PMID: 9080560.

37. Kakwani N, Wagstaff A. E. VD. Socioeconomic inequalities in health: measurement, computation, and statistical inference. J Econ. 1997;77(1):87-103.

38. Van de Poel E, Flores G, Ir P, O'Donnell O, Van Doorslaer E. Can vouchers deliver? An evaluation of subsidies for maternal health care in Cambodia. Bull World Health Organ 2014;92(5):331-339. PubMed PMID: 24839322. Pubmed Central PMCID: 4007125

39. Azmat SK, Shaikh BT, Hameed W, Bilgrami M, Mustafa M, Ali M, et al. Rates of IUCD discontinuation and its associated factors among the clients of a social franchising network in Pakistan. BMC Womens Health. 2012;12(1):8.

40. Azmat SK, Ahmed S, Hameed W, Bilgrami M, A K, khan AA, et al. performance and measurement of a community-based distribution model of family planning services in Pakistan. Journal of Pakistan Medical Association. 2013 Apr;63(4 Suppl 3):S40-S45. PubMed PMID: 24386729.

41. Department of Reproductive Health and Research. Public policy and franchising reproductive health: current evidence and future directions Geneva: World Health Organization, 2007. [cited March 23, 2016]. Available from: http://www.who.int/reproductivehealth/publications/health_systems/ 9789241596021/en/. Accessed 23 Mar 2019.

42. Azmat SK, Hameed W, Mustafa G, Hussain W, Ahmed A, Bilgrami M. IUD discontinuation rates, switching behavior, and user satisfaction: findings from a retrospective analysis of a mobile outreach service program in Pakistan. Int J Women's Health 2013;5:19-27. PubMed PMID: 23359788. Pubmed Central PMCID: 3555552.

43. Hameed W, Azmat SK, Ishaque M, Hussain W, Munroe E, Mustafa G, et al. Continuation rates and reasons for discontinuation of intra-uterine device in three provinces of Pakistan: results of a 24-month prospective client follow-up. Health Research Policy and Research. 201525 November 2015;13 (Suppl 1)(53).

44. Hameed W, Azmat SK, Ali M, Ishaque M, Abbas G, Munroe E, et al. Comparing Effectiveness of Active and Passive Client Follow-Up Approaches in Sustaining the Continued Use of Long Acting Reversible Contraceptives (LARC) in Rural Punjab: A Multicentre, Non-Inferiority Trial. PloS one. 2016; 11(9). Pubmed Central PMCID: PMC5008757.
45. Government of Pakistan. Pakistan Economic Survey, 2012-13. Islamabad: Finance Division, Economic Advisor's Wing, 2013. [cited October 11, 2016]. Available from: http://www.finance.gov.pk/survey/chapters_13/ HGHLIGHTS\%202013.pdf. Accessed 23 Mar 2019.

46. Dingle A, Powell-Jackson T, Goodman C. A decade of improvements in equity of access to reproductive and maternal health services in Cambodia, 2000-2010. Int J Equity Health 2013 Jul 09;12:51. PubMed PMID: 23837577. Pubmed Central PMCID: 3723953.

47. Chakraborty NM, Firestone R, Bellows N. Equity monitoring for social marketing: use of wealth quintiles and the concentration index for decision making in HIV prevention, family planning, and malaria programs. BMC Public Health. 2013;13 Suppl 2:S6. PubMed PMID: 23902715. Pubmed Central PMCID: 3684531

48. Temmerman M, Khosla R, Bhutta ZA, Bustreo F. Towards a new global strategy for Women's, Children's and Adolescents' Health British Medical Journal 2015;351:h4414. PubMed PMID: 26371228.

49. United Nations. Sustainable development goals. New York: United Nations, 2016 [cited July 2017]. Available from: https://sustainabledevelopment.un. org/?menu=1300. Accessed 23 Mar 2019.

\section{Ready to submit your research? Choose BMC and benefit from:}

- fast, convenient online submission

- thorough peer review by experienced researchers in your field

- rapid publication on acceptance

- support for research data, including large and complex data types

- gold Open Access which fosters wider collaboration and increased citations

- maximum visibility for your research: over $100 \mathrm{M}$ website views per year

At BMC, research is always in progress.

Learn more biomedcentral.com/submissions 